\title{
ON THE COMPLEXITY OF REINFORCEMENT IN GRAPHS
}

\author{
NADER JAFARI RAD \\ Department of Mathematics \\ Shahrood University of Technology \\ Shahrood, Iran \\ e-mail: n.jafarirad@gmail.com
}

\begin{abstract}
We show that the decision problem for $p$-reinforcement, $p$-total reinforcement, total restrained reinforcement, and $k$-rainbow reinforcement are NP-hard for bipartite graphs.
\end{abstract}

Keywords: domination, total domination, total restrained domination, $p$ domination, $k$-rainbow domination, reinforcement, NP-hard.

2010 Mathematics Subject Classification: 05C69.

\section{REFERENCES}

[1] M. Blidia, M. Chellali and L. Volkmann, Some bounds on the p-domination number in trees, Discrete Math. 306 (2006) 2031-2037.

doi:10.1016/j.disc.2006.04.010

[2] J.R.S. Blair, W. Goddard, S.T. Hedetniemi, S. Horton, P. Jones and G. Kubicki, On domination and reinforcement numbers in trees, Discrete Math. 308 (2008) 11651175 .

doi:10.1016/j.disc.2007.03.067

[3] B. Brešar, M.A. Henning and D.F. Rall, Rainbow domination in graphs, Taiwanese J. Math. 12 (2008) 213-225.

[4] B. Brešar an T.K. Šumenjak, On the 2-rainbow domination in graphs, Discrete Appl. Math. 155 (2007) 2394-2400. doi:10.1016/j.dam.2007.07.018

[5] M. Chellali, O. Favaron, A. Hansberg and L. Volkmann, $k$-domination and $k$ independence in graphs: A survey, Graphs Combin. 28 (2012) 1-55. doi:10.1007/s00373-011-1040-3 
[6] X.-G. Chen, D-X. Ma and L. Sun, On total restrained domination in graphs, Czechoslovak Math. J. 55 (2005) 165-173.

doi:10.1007/s10587-005-0012-2

[7] J. Cyman and J. Raczek, On the total restrained domination number of a graph, Australas. J. Combin. 36 (2006) 91-100.

[8] G.S. Domke and R.C. Laskar, The bondage and reinforcement numbers of $\gamma_{f}$ for some graphs, Discrete Math. 167/168 (1997) 249-259. doi:10.1016/S0012-365X(97)00232-X

[9] J.E. Dunbar, T.W. Haynes, U. Teschner and L. Volkmann, Bondage, insensitivity, and reinforcement, in: T.W. Haynes, S.T. Hedetniemi and P.J. Slater (Ed(s)), Domination in Graphs: Advanced Topics (Marcel Dekker, New York, 1998) 471-489.

[10] J.F. Fink and M.S. Jacobson, $n$-domination in graphs, in: Y. Alavi and A.J. Schwenk (Ed(s)), Graph Theory with Applications to Algorithms and Computer Science (Wiley, New York, 1985) 283-300.

[11] M.R. Garey and D.S. Johnson, Computers and Intractability: A Guide to the Theory of NP-Completeness (Freeman, San Francisco, 1979).

[12] T.W. Haynes, S.T. Hedetniemi and P.J. Slater, Fundamentals of Domination in Graphs (Marcel Dekker, Inc., New York, 1998).

[13] M.A. Henning, N. Jafari Rad and J. Raczek, A note on total reinforcement in graphs, Discrete Appl. Math. 159 (2011) 1443-1446. doi:10.1016/j.dam.2011.04.024

[14] M.A. Henning and A. Yeo, Total Domination in Graphs (Springer Verlag, New York, 2013).

[15] F.-T. Hu and M.Y. Sohn, The algorithmic complexity of bondage and reinforcement problems in bipartite graphs, Theoret. Comput. Sci. 535 (2014) 46-53. doi:10.1016/j.tcs.2014.04.005.

[16] F.-T. Hu and J.-M. Xu, On the complexity of the bondage and reinforcement problems, J. Complexity 28 (2012) 192-201. doi:10.1016/j.jco.2011.11.001

[17] N. Jafari Rad and L. Volkmann, Total restrained reinforcement in graphs, AKCE Int. J. Graphs Comb. 13 (2016) 16-21. doi:10.1016/j.akcej.1016.02.003

[18] J. Kok and C.M. Mynhardt, Reinforcement in graphs, Congr. Numer. 79 (1990) $225-231$.

[19] Y. Lu, F.-T. Hu and J.-M. Xu, On the p-reinforcement and the complexity, J. Comb. Optim. 29 (2015) 389-405. doi:10.1007/s10878-013-9597-9

[20] D. Rautenbach and L. Volkmann, New bounds on the $k$-domination number and the k-tuple domination number, Appl. Math. Lett. 20 (2007) 98-102. doi:10.1016/j.aml.2006.03.006 
[21] R.S. Shaheen, Bounds for the 2-domination number of toroidal grid graphs, Int. J. Comput. Math. 86 (2009) 584-588.

doi:10.1080/00207160701690284

[22] N. Sridharan, M.D. Elias and V.S.A. Subramanian, Total reinforcement number of a graph, AKCE Int. J. Graphs Combin. 4 (2007) 197-202.

[23] C. Tong, X. Lin, Y. Yang and M. Luo, 2-rainbow domination of generalized Petersen graphs $P(n, 2)$, Discrete Appl. Math. 157 (2009) 1932-1937.

doi:10.1016/j.dam.2009.01.020

[24] Y. Wu and N. Jafari Rad, Bounds on the 2-rainbow domination number of graphs, Graphs Combin. 29 (2013) 1125-1133.

doi:10.1007/s00373-012-1158-y

[25] Y. Wu and H. Xing, Note on 2-rainbow domination and Roman domination in graphs, Appl. Math. Lett. 23 (2010) 706-709.

doi:10.1016/j.aml.2010.02.012

[26] G. Xu, 2-rainbow domination in generalized Petersen graphs $P(n, 3)$, Discrete Appl. Math. 157 (2009) 2570-2573.

doi:10.1016/j.dam.2009.03.016

[27] J.H. Zhang, H.L. Liu and L. Sun, Independence bondage number and reinforcement number of some graphs, Trans. Beijing Inst. Tech. 23 (2003) 140-142.

Received 14 April 2015

Revised 8 July 2015

Accepted 2 January 2016 